\title{
OBITUARIO
}

\section{ALICIA ISABEL LUTZ}

(1949-2016)

El 21 de diciembre de 2016 falleció en la ciudad de Corrientes la Dra. Alicia Isabel Lutz, "Pelusa" como la conocimos todos. Se desempeñó como Profesora Titular de la asignatura Paleontología de la FACENA-UNNE e Investigadora Independiente del CONICET en el Centro de Ecología Aplicada del Litoral. Alicia nació el 17 de octubre de 1949 en Oberá (Misiones) y arribó a la ciudad de Corrientes en 1968 para estudiar Biología. Egresó como Profesora en Biología y Licenciada en Botánica (1994) de la FACENA-UNNE. Se desempeñó en varios cargos docentes hasta alcanzar la titularidad de la asignatura Paleontología en 1999; también desarrolló actividades de gestión como Subdirectora del PRINGEPA-CONICET (19952000) y como Directora de la Carrera del Profesorado en Biología

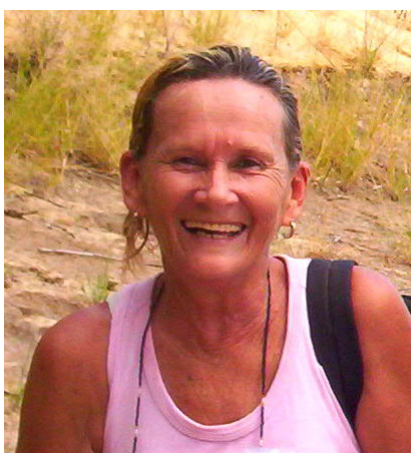
(FACENA-UNNE). Su actuación dentro del ámbito de la investigación estuvo centrada en la Paleobotánica al tiempo que fue, junto al Dr. Rafael Herbst, una de las precursoras en el estudio de la geología y estratigrafía de Corrientes y de los leños fósiles del Mioceno tardíoPlioceno de la Mesopotamia Argentina, para luego dedicarse a los leños del Pérmico-Triásico y Jurásico de la Argentina y Chile, donde también realizó grandes contribuciones. Su tesis doctoral se centró en el estudio del registro paleobotánico de las secuencias triásicas de Marayes (San Juan). Su permanente entusiasmo por la Paleontología la llevó a constituirse en un pilar fundamental en la creación del grupo de investigación en Paleontología de vertebrados y en la consolidación y continuación de varias líneas de investigación dentro de la Paleobotánica en el CECOAL-CONICET-UNNE. Fue una gran impulsora en el crecimiento y establecimiento de la colección Paleontológica de la UNNE "Dr. Rafael Herbst" como uno de los repositorios paleontológicos de referencia en nuestro país. A pesar de ser "paleobotánica”, Alicia siempre fue una entusiasta bióloga-botánica y paleontóloga general, ya que tanto en sus campañas paleontológicas (Patagonia, Cuyo, etc.) como en sus salidas de fin de semana herborizaba plantas para las colecciones del IBONE, colectaba bivalvos y otros restos fósiles en las barrancas de Empedrado (Corrientes). También fue fundamentalmente una entusiasta "paleovertebradóloga", y muy particularmente una enamorada de "Toropí", un yacimiento de vertebrados localizado en cercanías a la localidad de Bella Vista, Corrientes. Su impulso desembocó en la creación en el mes de junio de 2015 del primer Museo Paleontológico de la provincia de Corrientes, el "Paleomuseo Toropí", de la "Reserva Paleontológica del Arroyo Toropí" y de la sanción de la ley provincial 6165/12 que protege estos afloramientos paleontológicos. Asimismo cumplió un rol clave en la creación del Museo de Ciencias Naturales de Formosa en Villa Escolar, que cuenta con una abundante colección de piezas fósiles. Fue una importante e incansable formadora de recursos humanos, hasta tal punto de que muchos de los actuales integrantes del área de Paleontología del CECOAL estuvieron a su cargo en algún momento de su carrera como becarios o investigadores. $\mathrm{Su}$ legado científico se traduce a numerosas publicaciones y presentaciones a diversas reuniones científicas, siendo muchas de estas contribuciones pioneras en su temática por lo que siguen siendo ampliamente citadas en la literatura científica. Desde un punto de vista personal, quienes tuvimos el privilegio de trabajar y compartir muchos momentos con Alicia, resaltamos su espíritu noble y de ayuda constante así como su compromiso con el trabajo. Fue, en resumidas cuentas, una gran amiga y compañera y enorme maestra. Hasta siempre "Pelusa".

Alfredo E. Zurita, Alexandra Crisafulli y Oscar F. Gallego 
